\title{
A IMPORTÂNCIA DO ESTUDO DE PARTICIPAÇÕES GOVERNAMENTAIS NOS CURSOS DE ENGENHARIA DE PETRÓLEO
}

Bruno Ghisleri Neves - brunoneves@id.uff.br

Universidade Federal Fluminense - UFF

Escola de Engenharia - TCE

Departamento de Engenharia Química e de Petróleo- TEQ

Rua Passo da Pátria, 156 - Bloco E - Sala 247

21.210-240 - Niterói - RJ

Raphael Abreu Borges - raphaelborges@ufrj.br-

Universidade Federal do Rio de Janeiro - UFRJ

Faculdade Nacional de Direito - FND

Rua Moncorvo Filho, 8 - Centro

20.211-340 - Rio de Janeiro - RJ

Resumo: O presente artigo tem como objetivo produzir conteúdo a partir do estudo acerca das participações governamentais no âmbito curricular dos cursos de Engenharia de Petróleo de três universidades do Brasil. Assim, fora elaborada uma análise crítica envolvendo a importância do tema para o país e empresas na área versus a quantidade de disciplinas relacionadas presentes na grade dos cursos de graduação em Engenharia de Petróleo da Universidade Federal Fluminense, Universidade Federal do Rio de Janeiro e Universidade Federal de Pelotas. Para elaboração desta tarefa, foi feito um levantamento bibliográfico sobre as participações governamentais existentes na legislação brasileira, leis e resoluções em vigor utilizadas para normatização e auditorias por parte do órgão regulador brasileiro e a grade curricular dos cursos de graduação citados anteriormente. O resultado de aprendizagem obtido com este projeto foi aferido pela análise da importância econômica e mercadológica do tema e a pouca abordagem acerca da temática durante a graduação do engenheiro de petróleo. Por fim, o trabalho apresenta sugestões para as universidades, a fim de enriquecer o conteúdo ministrado aos alunos, e como consequência disso, aprimorar a formação dos estudantes visando ao mercado de trabalho.

Palavras-chave: Participações Governamentais. Petróleo. Legislação. Ensino-aprendizado.

\section{INTRODUÇÃO}

O primeiro poço de petróleo foi perfurado em 1859 por Edwin L. Drake, na cidade de Titusville, nos Estados Unidos da América (WDL, 2017). Deste marco histórico até os dias de hoje, diversas técnicas de exploração e produção foram inventadas e aprimoradas para manter o funcionamento de uma das indústrias mais importantes do mundo, responsável por quase $4 \%$ do Produto Interno Bruto (PIB) mundial em 2019 (ÉPOCA NEGÓCIOS, 2020). 
A frase "Ao longo da história do petróleo... nenhum outro negócio define de forma tão completa e radical o significado do risco e da recompensa" de Daniel Yergin (2010), uma das maiores autoridades globais em economia do petróleo, explicita a importância deste recurso energético fundamental para o mundo.

Corroborando os parágrafos acima, faz-se necessário o conhecimento das participações governamentais, consideradas compensações financeiras à União, Estados e Municípios oriundas da exploração e produção de petróleo e gás natural em território, plataforma continental, mar territorial ou zona econômica exclusiva do Brasil (ANP, 2019).

$\mathrm{O}$ órgão regulador das atividades relacionadas às indústrias de petróleo, gás natural e biocombustíveis em território brasileiro é a Agência Nacional do Petróleo, Gás Natural e Biocombustíveis (ANP), criada em 1997 pela Lei do Petróleo (Lei n ${ }^{\circ}$ 9.478/97), responsável direta no caso das participações governamentais, pelo controle, auditorias, cálculos e distribuições dos valores arrecadados aos respectivos beneficiários.

Tendo em vista a importância das participações governamentais para o Brasil (movimentando cerca de R $\$ 126$ bilhões em 2019, segundo a ANP) e ser imprescindível para a economia de estados como o Rio de Janeiro, representando 30 \% do PIB estadual (G1, 2019), surgiram os seguintes questionamentos: se todas as operadoras do país necessitam de profissionais para esta área, por que este conteúdo é tão pouco ministrado ao longo do curso de formação de um engenheiro de petróleo? E por que uma área da indústria de petróleo com tanto peso no orçamento nacional não tem tanta visibilidade nas aulas ministradas nesses cursos?

$\mathrm{Na}$ seção 4, será demonstrada a quantidade de disciplinas ofertadas, pelas universidades analisadas, que abordam a temática das participações governamentais em meio a outras que envolvem atividades de cunho técnico para o engenheiro, como: prospecção, exploração, perfuração e produção em poços de petróleo.

Por fim, os autores realizam uma comparação entre as disciplinas existentes nas grades curriculares de cada universidade, analisando suas ementas e sugerindo alterações que visam ao aprimoramento da formação acadêmica dos alunos.

\section{METODOLOGIA}

Devido aos questionamentos que surgiram no tópico anterior, o presente trabalho irá explicar a importância dessa área do setor petrolífero para a formação do engenheiro de petróleo, analisando a legislação vigente, grades curriculares de três cursos de Engenharia de Petróleo do Brasil (Universidade Federal Fluminense, Universidade Federal do Rio de Janeiro e Universidade Federal de Pelotas), tendo foco nas disciplinas relacionadas com as participações governamentais e suas respectivas cargas horárias.

Por fim, será realizada uma discussão acerca do tema, apresentando sugestões para melhoria dos cursos de graduação analisados, visando sempre à formação de um profissional mais completo nas universidades brasileiras.

\section{LEGISLAÇÃO EM VIGOR}

Diante da análise proposta, trataremos, a partir desse momento, de observar sobre o estudo das legislações acerca das participações governamentais, sendo elas compreendidas em leis, portarias e resoluções, tendo em vista o grau de importância financeira que exercem no contexto da economia nacional. 


\subsection{Preços de Referência do Petróleo e Gás Natural}

Preliminarmente, faz-se necessário abordar o chamado preço de referência que exercerá fundamental papel sobre os royalties e a participação especial, duas das três participações governamentais que elencaremos a seguir.

\section{Preço de Referência do Petróleo}

De acordo com o Artigo 47 da Lei 9.478/1997 e com o Capítulo IV do Decreto $\mathrm{n}^{\mathrm{o}}$ 2.705/1998, a Resolução ANP n 703 de 26 de setembro de 2017 estabelece os critérios para fixação do preço de referência do petróleo produzido mensalmente em cada campo produtor a serem adotados para fins de cálculo das participações governamentais (royalties e participação especial). Como uma de suas principais definições, a Resolução ANP nº 703/2017 indica que o preço de referência do petróleo será o preço por unidade de volume, expresso em moeda nacional, real por metro cúbico $\left(\mathrm{R} \$ / \mathrm{m}^{3}\right)$, para o petróleo produzido em cada campo, a ser determinado pela ANP por meio da própria Resolução. Além disso, a mesma Resolução traz diversas diretrizes que irão servir para a aplicação da Lei $\mathrm{n}^{\circ}$ 9.478/1997 que abordaremos ao longo deste trabalho.

Correntes e tipos de petróleo; cálculo do preço de referência do petróleo nacional; cálculo do preço de referência do petróleo para empresa de pequeno porte (exceções à regra) e a função da Agência de Informação de Preços são algumas das disposições trazidas pela Resolução ANP $n^{\circ}$ 703/2017. Além dessas, passamos a destacar o tempo de transição presente no Artigo 11 dessa Resolução, alinhado com o Artigo $7^{\circ}-\mathrm{B}, \S^{\circ}$, do Decreto ${ }^{\circ} 2.705 / 1998$. Por meio dele, é possível estabelecer os cálculos para a identificação do preço de referência do petróleo, o que também demandará o conhecimento sobre preço mínimo do petróleo de acordo com a Portaria ANP n 206 de 29 de agosto de 2000:

Art. 11. A implementação desta Resolução se dará de forma gradual conforme tabela abaixo.

\begin{tabular}{|l|l|}
\hline Período & Preço de Referência do Petróleo \\
\hline 2018 & $80 \%$ PM 206+ 20\% PRP \\
\hline 2019 & $60 \%$ PM 206 + 40\% PRP \\
\hline 2020 & $40 \%$ PM 206 +60\% PRP \\
\hline 2021 & $20 \%$ PM 206 + 80\% PRP \\
\hline A partir de 2022 & $100 \%$ PRP \\
\hline
\end{tabular}

Onde:

PM 206 - Preço Mínimo do petróleo, calculado nos termos da Portaria ANP $n^{\circ} 206 / 2000$.

PRP - Preço de Referência do Petróleo, apurado nos temos desta Resolução.

\section{Preço de Referência do Gás Natural}

Assim como no caso do petróleo, o preço de referência do gás natural também é analisado à luz do Artigo 47 da Lei 9.478/1997 e do Capítulo IV do Decreto n 2.705/1998, porém, temse o Artigo $8^{\circ}$ deste mesmo Decreto como regra, sendo a média ponderada dos preços de venda do gás natural, livres dos tributos incidentes sobre a venda, de acordo com os contratos de 
fornecimento celebrados entre o concessionário e os compradores do gás natural produzido na área da concessão, deduzidas as tarifas relativas ao transporte do gás natural.

Para as situações previstas no $\S 4^{\circ}$ do Artigo $8^{\circ}$ do Decreto $n^{\circ} 2.705 / 1998$, a Resolução ANP $\mathrm{n}^{\circ} 40$ de 14 de dezembro de 2009 estabelece os critérios de fixação de preço de referência do gás natural (PRGN) produzido nos campos objeto de concessão pela ANP, obtendo-os a partir de cálculos e utilizando-os para o pagamento das participações governamentais (royalties e participação especial).

O PRGN a ser aplicado para o gás natural produzido durante o respectivo mês, em cada campo produtor, em reais por metro cúbico, na condição padrão de medição, fica definido como o somatório dos produtos das frações volumétricas do gás natural que, após o seu processamento, podem ser obtidas como condensado de gás natural (VCGN), gás liquefeito de petróleo (VGLP) e gás processado (VGP), pelos correspondentes preços (PCGN, PGLP e PGP, respectivamente).

\subsection{Participações Governamentais}

Conforme o exposto, tomaremos como maior referência a Lei $\mathrm{n}^{\circ} 9.478$ de 6 de agosto de 1997, que dispõe sobre a política energética nacional, as atividades relativas ao monopólio do petróleo, institui o Conselho Nacional de Política Energética e a Agência Nacional do Petróleo.

Em seu Artigo 45, a Lei $n^{\circ} 9.478 / 1997$ elenca os quatro modelos de participações governamentais, que, dentre esses, destacaremos os royalties, a participação especial e o pagamento pela ocupação ou retenção de área.

Art. 45. O contrato de concessão disporá sobre as seguintes participações governamentais, previstas no edital de licitação:

I - bônus de assinatura;

\section{II - royalties;}

III - participação especial;

IV - pagamento pela ocupacão ou retencão de área. (grifos nossos)

\section{Royalties}

Os royalties são uma compensação financeira devida pelos concessionários à União, Estados e Municípios, em função da produção de petróleo e gás natural no território nacional. $\mathrm{O}$ valor dos royalties, a ser pago mensalmente pelas empresas, em relação a cada campo produtor, é obtido pela multiplicação de três fatores: (1) alíquota dos royalties do campo produtor; (2) produção mensal de petróleo e gás natural e (3) preço de referência do petróleo e gás natural no mês.

Nesse contexto, a ANP é responsável por calcular e distribuir, nos termos da legislação vigente, os royalties aos entes beneficiários (União, Estados e Municípios). A distribuição da parcela de 5\% dos royalties referentes aos regimes de concessão e cessão onerosa está delimitada na Lei $n^{\circ} 7.990 / 1989$ e no Decreto $n^{\circ}$ 1/1991; a distribuição da parcela acima de $5 \%$ dos royalties dos regimes de concessão e cessão onerosa está estabelecida na Lei ${ }^{\circ}$ 9.478/1997 e no Decreto $n^{\circ} 2.705 / 1998$ e, por fim, os royalties referentes ao regime de partilha de produção obedecem ao disposto na Lei ${ }^{\circ} 12.351 / 2010$.

A Lei $\mathrm{n}^{\circ} 7.990$ de 28 de dezembro de 1989 institui, para os Estados, Distrito Federal e Municípios, compensação financeira pelo resultado da exploração de petróleo ou gás natural, de recursos hídricos para fins de geração de energia elétrica, de recursos minerais em seus 
respectivos territórios, plataforma continental, mar territorial ou zona econômica exclusiva. Dessa maneira, destaca-se o disposto no Artigo $6^{\circ}$ :

Art. 6으 A exploração de recursos minerais ensejará o recolhimento da Compensação Financeira pela Exploração de Recursos Minerais (CFEM), nos termos do $\S 1^{\circ}$ art. 20 da Constituição Federal, por ocasião:

I - da primeira saída por venda de bem mineral;

II - do ato de arrematação, nos casos de bem mineral adquirido em hasta pública;

III - do ato da primeira aquisição de bem mineral extraído sob o regime de permissão de lavra garimpeira; e

IV - do consumo de bem mineral.

Em consonância com a Lei ${ }^{\circ} 7.990 / 1989$, há o Decreto $n^{\circ} 1$ de 11 de janeiro de 1991 que regulamenta o pagamento da compensação financeira instituída pela Lei no 7.990/1989. Depreende-se do seu Artigo 17, que a compensação financeira devida pela Petróleo Brasileiro S.A. (Petrobras) e suas subsidiárias aos Estados, Distrito Federal e Municípios, correspondente a 5\% sobre o valor do óleo bruto, do xisto betuminoso e do gás natural extraídos de seus respectivos territórios, onde se fixar a lavra do petróleo ou se localizarem instalações marítimas ou terrestres de embarque ou desembarque de óleo bruto ou de gás natural, operados pela Petrobras, será paga em percentuais, sendo 3,5\% destinados aos Estados produtores; $1 \%$ aos Municípios produtores e 0,5\% para os Municípios onde se localizarem instalações marítima ou terrestres de embarque ou desembarque de óleo bruto ou gás natural.

A Lei $\mathrm{n}^{\circ}$ 9.478/1997, a partir do seu Artigo 47, trata de estabelecer que o recolhimento dos royalties será mensal, até o último dia útil do mês seguinte ao mês da produção, assim como descreve como será determinada cada alíquota, além de ratificar que a apuração dos royalties se dará por campos, sendo o preço de acordo com o estabelecido em contrato.

Por sua vez, o Decreto $\mathrm{n}^{\mathrm{o}} 2.705$ de 3 de agosto de 1998 define critérios para cálculo e cobrança das participações governamentais de que trata a Lei $n^{\circ}$ 9.478/1997 aplicáveis às atividades de exploração, desenvolvimento e produção de petróleo e gás natural. Por meio desse decreto, identificamos, ao longo dos seus artigos, os volumes de incidência, sendo eles o volume total de petróleo e gás natural produzido em cada campo e os volumes medidos nos pontos de medição fiscal definidos no Plano de Desenvolvimento do campo, por exemplo. Além disso, há os volumes excluídos da incidência, o preço de referência para o petróleo e para o gás natural, assim como o preço de venda.

Para além dessas legislações, há a Lei n 12.351, de 22 de dezembro de 2010, que dispõe sobre a exploração e a produção de petróleo, de gás natural e de outros hidrocarbonetos fluidos, sob o regime de partilha de produção, em áreas do pré-sal e em áreas estratégicas. De acordo com seu Artigo 27, o contrato de partilha de produção preverá 2 fases, sendo elas: a exploração, que incluirá as atividades de avaliação de eventual descoberta de petróleo ou gás natural, para determinação de sua comercialidade e a produção, que incluirá as atividades de desenvolvimento. Ainda, o Artigo $6^{\circ}$ traz as importantes disposições sobre os custos e investimentos no regime de partilha que devem ser observados:

Art. $6^{\circ}$ Os custos e os investimentos necessários à execução do contrato de partilha de produção serão integralmente suportados pelo contratado, cabendo-lhe, no caso de descoberta comercial, a sua restituição nos termos do inciso II do art. $2^{\circ}$.

Parágrafo único. A União, por intermédio de fundo específico criado por lei, poderá participar dos investimentos nas atividades de exploração, avaliação, 
desenvolvimento e produção na área do pré-sal e em áreas estratégicas, caso em que assumirá os riscos correspondentes à sua participação, nos termos do respectivo contrato.

Por fim, as seguintes legislações também são utilizadas com a finalidade de distribuição dos royalties: a Portaria ANP $\mathrm{n}^{\circ}$ 29/2001, que aborda os Municípios afetados pelas operações de embarque e desembarque; a Lei $\mathrm{n}^{\circ}$ 7.525/1986, que demonstra o conceito de área geoeconômica; o Decreto $\mathrm{n}^{\circ} 93.189 / 1986$, que indica as linhas de projeção; a Lei $\mathrm{n}^{\circ}$ 12.858/2013, que apresenta a destinação para educação e saúde e a Lei no $12.734 / 2012$ que está parcialmente suspensa, tendo em vista a deferimento da medida cautelar no âmbito da Ação Direta de Inconstitucionalidade (ADI) 4917 no Supremo Tribunal Federal.

\section{Participação Especial}

Para as participações especiais, a Lei no 9.478/1997 reservou as disposições a partir do seu Artigo 50. Assim, percebe-se que a participação especial incidirá nos casos de grande volume de produção ou de grande rentabilidade e será aplicada sobre a receita bruta da produção, deduzidos os royalties, os investimentos na exploração, os custos operacionais, a depreciação e os tributos previstos na legislação em vigor.

Em especial atenção, a Resolução ANP n ${ }^{\circ}$ 12, de 21 de fevereiro de 2014, estabelece os procedimentos para a apuração, pelos concessionários das atividades de produção de petróleo, gás natural ou ambos, da participação especial prevista no Artigo 50 da Lei no 9.478/1997, em complementação ao Capítulo VII do Decreto nº 2.705/1998.

Desse modo, verifica-se que a participação especial constitui uma compensação financeira extraordinária devida trimestralmente pelos concessionários das atividades de produção de petróleo, gás natural ou ambos, com relação a cada campo, somente em casos de grande volume de produção ou de grande rentabilidade. Deve-se ressaltar que a alíquota incide sobre a receita líquida da produção do campo, sendo essa a base de cálculo, em que a alíquota varia de $0 \%$ a $40 \%$.

\section{Pagamento pela Ocupação ou Retenção de Área}

Não menos importante, há o pagamento de ocupação ou retenção de área, que é identificado no Artigo 51 da Lei $n^{\circ}$ 9.478/1997 e regulamentada no Artigo 28 do Decreto $n^{\circ}$ 2.705/1998. Assim, entende-se que esse pagamento será realizado anualmente, sendo fixado por quilômetro quadrado ou fração da superfície do bloco, na forma da regulamentação por decreto do Presidente da República. Da mesma forma, o valor do pagamento pela ocupação ou retenção de área será aumentado em percentual a ser estabelecido pela ANP, sempre que houver prorrogação do prazo de exploração.

Assim, temos que o valor é pago anualmente, no dia 15 de janeiro do ano subsequente, mesmo em caso de suspensão das atividades contratuais e que varia conforme a etapa do contrato, sempre observando os limites previstos a partir do Artigo 28 do Decreto $\mathrm{n}^{\circ}$ 2.705/1998. Haverá, então, um acréscimo de $100 \%$ em caso de prorrogação da Fase de Exploração e para a Etapa de Desenvolvimento e haverá um acréscimo de $900 \%$ para a Fase de Produção.

Para os casos de cessão de direitos ou devolução de área, o pagamento pela ocupação ou retenção de área dar-se-á no ato de assinatura do respectivo evento. 


\section{ANÁLISE DA ESTRUTURA CURRICULAR DAS UNIVERSIDADES}

Nesse tópico, serão expostas as análises das estruturas curriculares de três universidades brasileiras selecionadas pelos autores, acompanhadas de sugestões de melhorias que visam ao aprimoramento da formação acadêmica dos estudantes de Engenharia de Petróleo.

\subsection{Universidade Federal Fluminense - UFF}

O curso de Engenharia de Petróleo ofertado pela Universidade Federal Fluminense totaliza 3.907 horas de aula para a obtenção do título de Bacharel em Engenharia de Petróleo, divididas em 67 disciplinas. Durante o curso de graduação, o aluno tem conteúdo ministrado especificamente sobre participações governamentais em apenas uma disciplina obrigatória.

A disciplina denominada "Estrutura e Organização da Indústria do Petróleo", com carga horária composta por 60 horas de aulas teóricas, tem descrito o ensino de participações governamentais em sua ementa, representando apenas $1,5 \%$ da integralização do currículo dos alunos. (UFF, 2013)

Analisando a ementa desta disciplina, são elencados quinze assuntos a serem lecionados ao longo do período letivo. As participações governamentais são citadas apenas uma vez na ementa, resultando em apenas quatro horas de aula em média para ministrá-las.

\subsection{Universidade Federal do Rio de Janeiro - UFRJ}

O curso de Engenharia de Petróleo ofertado pela Universidade Federal do Rio de Janeiro totaliza 4.383 horas de aula para a obtenção do título de Bacharel em Engenharia de Petróleo, divididas em 77 disciplinas. Durante o curso de graduação, o aluno tem conteúdo ministrado especificamente sobre participações governamentais em apenas uma disciplina obrigatória.

A disciplina denominada "Regulamento e Legislação de Petróleo", com carga horária composta por 45 horas de aulas teóricas e 15 horas de aulas práticas, tem descrito o ensino de participações governamentais em sua ementa, representando apenas $1,4 \%$ da integralização do currículo dos alunos. (UFRJ, 2010)

Analisando a ementa desta disciplina, são elencados cinco assuntos a serem lecionados ao longo do período letivo. As participações governamentais são citadas apenas uma vez na ementa, resultando em apenas doze horas de aula em média para ministrá-las.

\subsection{Universidade Federal de Pelotas - UFPel}

O curso de Engenharia de Petróleo ofertado pela Universidade Federal de Pelotas totaliza 5.134 horas de aula para a obtenção do título de Bacharel em Engenharia de Petróleo, divididas em 70 disciplinas. Durante o curso de graduação, o aluno não tem contato com as participações governamentais em nenhuma disciplina. (UFPEL, 2016)

\subsection{Sugestões dos Autores}

A partir da síntese da grade curricular dos cursos de Engenharia de Petróleo das universidades citadas nos itens 4.1 a 4.3, os autores elaboraram sugestões que podem ser implementadas de forma simples e imediata no conteúdo a ser ministrado para os estudantes ao longo de sua formação acadêmica. Com isso, pode ser observado, na Tabela 1, o que pode ser feito especificamente para o caso da UFPel, que não possui disciplinas relacionadas com tema central do artigo. Para a UFF e UFRJ, recomendamos o maior enfoque neste tema ao longo das disciplinas existentes e/ou o desmembramento do assunto em uma nova disciplina obrigatória 
"Os desafios para formar hoje o engenheiro do amanhã"

e/ou opcionais, visando à formação de alunos mais preparados para o mercado de trabalho na área.

Tabela 1 - Análise das universidades

\begin{tabular}{|c|c|c|c|c|}
\hline Universidades & $\begin{array}{c}\text { Disciplinas } \\
\text { relacionadas às PGs. }\end{array}$ & $\begin{array}{c}\text { Carga } \\
\text { Horária }\end{array}$ & Panorama atual & \multicolumn{1}{|c|}{ O que pode ser feito } \\
\hline UFF & $\begin{array}{c}\text { "Estrutura e } \\
\text { Organização da } \\
\text { Indústria do Petróleo" }\end{array}$ & $\begin{array}{c}60 \mathrm{~h} \\
\text { teóricas }\end{array}$ & $\begin{array}{c}\text { A ementa lista } 15 \text { temas } \\
\text { a serem abordados } \\
\text { dentro da disciplina, } \\
\text { resultando em 4h de aula } \\
\text { por tema (média). }\end{array}$ & $\begin{array}{l}\text { - Dar mais enfoque ao tema, } \\
\text { devido à sua importância para } \\
\text { o mercado de trabalho e } \\
\text { complexidade. }\end{array}$ \\
\hline UFRJ & $\begin{array}{c}\text { Legislação de Petróleo" } \\
\text { "Regulamento e }\end{array}$ & $\begin{array}{c}45 \mathrm{~h} \\
\text { teóricas e } \\
15 \mathrm{~h} \\
\text { práticas }\end{array}$ & $\begin{array}{c}\text { A ementa lista } 5 \text { temas a } \\
\text { serem abordados dentro } \\
\text { da disciplina, resultando } \\
\text { em 12h de aula por tema } \\
\text { (média). }\end{array}$ & $\begin{array}{l}\text { Estudo do desmembramento } \\
\text { deste tema em uma nova } \\
\text { disciplina obrigatória e/ou } \\
\text { opcional. }\end{array}$ \\
\hline UFPel & \multicolumn{2}{|c|}{ Não Possui } & - & $\begin{array}{l}\text { - Criação de disciplina } \\
\text { obrigatória e/ou opcional. }\end{array}$ \\
\hline
\end{tabular}

Fonte: elaboração própria.

\section{CONCLUSÃO}

Resta claro, portanto, que diante de uma temática tão complexa, o entendimento e análise das participações governamentais, sendo elas compreendidas, especialmente, em royalties e participação especial, tornam-se essenciais para desenvolvimento dos estudos em Engenharia de Petróleo.

Corroborando esse pensamento, destaca-se que essas participações governamentais são responsáveis por movimentar em $2019 \mathrm{R} \$ 126,2$ bilhões, sendo $\mathrm{R} \$ 23,4$ bilhões referentes aos royalties e $\mathrm{R} \$ 32,5$ bilhões referentes à participação especial, o que demonstra exatamente a substancial influência que exercem no contexto da economia brasileira.

Por todo o exposto, entende-se que as universidades brasileiras devem olhar com mais atenção para o assunto debatido e propor uma maior oferta de disciplinas obrigatórias e/ou opcionais em suas grades curriculares para abordar esse tema tão relevante, de modo a aprimorar a formação dos futuros engenheiros de petróleo.

\section{Agradecimentos}

Um agradecimento especial aos servidores da ANP, Rafael Chaves Camacho (Coordenador de Participação Especial), Roney Afonso Poyares (ex-Coordenador de Royalties) e Thiago Neves de Campos (Superintendente de Participações Governamentais) por auxílio com relação à dinâmica do trabalho e orientação quanto aos dados públicos para realização deste estudo.

\section{REFERÊNCIAS}

ANP. Resolução no 40, de 14 de dezembro de 2009. Estabelece os critérios de fixação do preço de referência do gás natural (PRGN) produzido nos campos objeto de concessão pela ANP. Disponível em: https://www.legisweb.com.br/legislacao/?id=111735. Acesso em: 27 mai. 2020 
ANP. Resolução $\mathbf{n}^{\mathbf{0}}$ 12, de 21 de fevereiro de 2014. Estabelece os procedimentos para a apuração, pelos concessionários das atividades de produção de petróleo, gás natural ou ambos, da participação especial prevista no art. 50 da Lei $\mathrm{n}^{\circ}$ 9.478, de 6 de agosto de 1997, em complementação ao Capítulo VII do Decreto n ${ }^{\circ} 2.705$, de 3 de agosto de 1998. Disponível em: http://legislacao.anp.gov.br/?path=legislacao-anp/resol-anp/2014/fevereiro\&item=ranp-12-2014. Acesso em: 27 mai. 2020.

ANP. Resolução $\mathbf{n}^{\mathbf{0}} \mathbf{7 0 3}$, de 26 de setembro de 2017. Estabelece os critérios para fixação do preço de referência do petróleo produzido mensalmente em cada campo. Disponível em: $\mathrm{http}$ ://legislacao.anp.gov.br/?path=legislacao-anp/resol-anp/2017/setembro\&item=ranp-703-

2017. Acesso em: 27 mai. 2020

ANP. Participações Governamentais. Disponível em: http://www.anp.gov.br/movimentacaoestocagem-e-comercializacao-de-gas-natural/transporte-de-gas-natural/acesso-a-gasodutos/2uncategorised/5169-participacoes-governamentais-kit-de-imprensa. Acesso em: 27 mai. 2020

BIBLIOTECA DIGITAL MUNDIAL. Titusville, Pensilvânia, 1896. Disponível em: https://www.wdl.org/pt/item/11368/. Acesso em: 27 mai. 2020.

BRASIL. Lei $\mathbf{n}^{\mathbf{0}}$ 7.990, de 28 de dezembro de 1989. Institui, para os Estados, Distrito Federal e Municípios, compensação financeira pelo resultado da exploração de petróleo ou gás natural, de recursos hídricos para fins de geração de energia elétrica, de recursos minerais em seus respectivos territórios, plataforma continental, mar territorial ou zona econômica exclusiva, e dá outras providências. (Art. 21, XIX da CF). Disponível em: http://www.planalto.gov.br/ccivil_03/LEIS/L7990.htm. Acesso em: 27 mai. 2020.

BRASIL. Decreto no 1, de 11 de janeiro de 1991. Regulamenta o pagamento da compensação financeira instituída pela Lei $\mathrm{n}^{\circ} 7.990$, de 28 de dezembro de 1989, e dá outras providências. Disponível em: http://www.planalto.gov.br/ccivil_03/decreto/1990-1994/D0001.htm. Acesso em: 27 mai. 2020.

BRASIL. Lei n 9.478, de 6 de agosto de 1997. Dispõe sobre a política energética nacional, as atividades relativas ao monopólio do petróleo, institui o Conselho Nacional de Política Energética e a Agência Nacional do Petróleo e dá outras providências. Disponível em: <http://www.planalto.gov.br/ccivil_03/leis/19478.htm>. Acesso em: 27 mai. 2020.

BRASIL. Decreto $\mathbf{n}^{\mathbf{2}} \mathbf{2 . 7 0 5}$, de 3 de agosto de 1998. Define critérios para cálculo e cobrança das participações governamentais de que trata a Lei ${ }^{\circ}$ 9.478, de 6 de agosto de 1997, aplicáveis às atividades de exploração, desenvolvimento e produção de petróleo e gás natural, e dá outras providências. Disponível em: http://www.planalto.gov.br/ccivil_03/decreto/D2705.htm. Acesso em: 27 mai. 2020.

BRASIL. Lei no 12.351, de 22 de dezembro de 2010. Dispõe sobre a exploração e a produção de petróleo, de gás natural e de outros hidrocarbonetos fluidos, sob o regime de partilha de produção, em áreas do pré-sal e em áreas estratégicas; cria o Fundo Social - FS e dispõe sobre sua estrutura e fontes de recursos; altera dispositivos da Lei no 9.478, de 6 de agosto de 1997; e dá outras providências. Disponível em: http://www.planalto.gov.br/ccivil_03/_Ato20072010/2010/Lei/L12351.htm. Acesso em: 27 mai. 2020. 
ÉPOCA NEGÓCIOS. Por que o preço do petróleo americano caiu abaixo de zero e como isso afeta mundo? 0 Disponível https://epocanegocios.globo.com/Economia/noticia/2020/04/por-que-o-preco-do-petroleoamericano-caiu-abaixo-de-zero-e-como-isso-afeta-o-mundo.html. Acesso em: 27 mai. 2020.

G1. Setor de petróleo e gás é responsável por $30 \%$ do PIB do estado do Rio, diz ABESPETRO durante Brasil offshore. Disponível em: https://g1.globo.com/rj/regiao-doslagos/noticia/2019/06/26/setor-de-petroleo-e-gas-e-responsavel-por-30percent-do-pib-doestado-do-rio-diz-abespetro-durante-brasil-offshore.ghtml. Acesso em: 27 mai. 2020

UFF. Fluxograma do Curso - Petróleo. Disponível em: http://petroleo.uff.br/fluxograma/. Acesso em: 28 mai. 2020.

UFPEL. Grade da Engenharia de Petróleo - Ingressantes 2016 (Ainda em uso. Disponível em: $\quad$ https://drive.google.com/file/d/1S1txsE8JW9bZfYOZCXEP4A1TFcdHx49K/view. Acesso em: 28 mai. 2020.

UFRJ. Habilitação de Graduação em Engenharia de Petróleo. Disponível em: https://siga.ufrj.br/sira/repositorio-curriculo/distribuicoes/24C6A6A4-92A4-F79C-4038E6D8B161E716.html. Acesso em: 28 mai. 2020.

YERGIN, Daniel. O Petróleo. São Paulo: Editora Paz e Terra, 2010.

\title{
THE IMPORTANCE OF STUDYING ABOUT GOVERNMENT PARTICIPATIONS IN PETROLEUM ENGINEERING UNDERGRADUATE COURSES
}

\begin{abstract}
The present paper aims to produce content about the Government Participations study at Petroleum Engineering graduation courses from three Brazilian Universities. To formulate a critical analysis involving the importance of the theme for the country and branch companies versus the number of related disciplines available in the Petroleum Engineering undergraduate courses at Universidade Federal Fluminense, Universidade Federal do Rio de Janeiro and Universidade Federal de Pelotas. In a way of elaborating this task, a bibliographic survey was made on the current Brazilian Legislation about Government Participations, Laws and Resolutions that are been currently used for standardization and audits by Brazilian Regulatory Agency and the curriculum of the undergraduate courses mentioned above. The acquired knowledge from this project was evaluated by the analysis of economic and market importance of the theme versus the short approach of the theme during the petroleum engineer's academic life. In conclusion, this paper presents suggestions for the analyzed universities to enrich the content taught to students and, therefore, improving their knowledge aiming at the job market.
\end{abstract}

Keywords: Governmental Participations. Petroleum. Legislation. Teach-Learning. 